\title{
ASSESSing AND Developing THE INDIVIDUAL AND TeAM WorK ATTRIBUTE
}

\author{
Genevieve Hoffart ${ }^{1}$, Katherine Gibbard ${ }^{1}$, Thomas ' $^{\text {Neill }}{ }^{1}$, Anders Nygren ${ }^{2}$, and William Rosehart ${ }^{2}$ \\ ${ }^{1}$ Department of Psychology, The University of Calgary, ${ }^{2}$ Schulich School of Engineering, The University of Calgary \\ gchoffar@ucalgary.ca
}

\begin{abstract}
Working effectively in teams is an essential skill that must be developed over the course of an engineering degree program. However, soft skills such as effective team behaviours can be difficult to assess and develop in students. Accordingly, the paper outlines our efforts to operationalize the Individual and Team Work attribute with the intention of outlining best practices in assessing, tracking, and enhancing the graduate attribute for both student development and accreditation purposes.

A survey comprised of 40 Likert-scale items and 3 open-ended response questions was administered to all undergraduate students at a large North American university. The survey resulted in key findings, including that students rated their team work competencies significantly lower than they rated the perceived importance of those competencies for success in the workplace. Additionally, females reported significantly lower satisfaction and support in their team experiences than male students. These findings and others resulted in 12 evidence-based recommendations to strategically support the Individual and Team Work attribute.
\end{abstract}

Keywords: engineering graduate attribute development, individual and team work, soft skill development, interpersonal skill development.

\section{INTRODUCTION}

Organizations use teams to tackle complex problems that can no longer be completed by one person alone [1]. Indeed, in industry, engineers are often assembled as parts of multi-disciplinary teams expected to work seamlessly together and tasked to create solutions to increasingly complex designs problems. In response to the team-based working landscape, educational institutions commonly employ team work in undergraduate courses to better prepare their graduates for an increasingly connected workforce.

Employers expect that engineering graduates' will be able to manage organizational tasks that draw heavily on soft skills [2]; yet, employers report a gap between the skills they expect students to have and their actual abilities [3]. This skills gap was confirmed during an industry advisory reception at the University of Calgary that hosted 37 industry professionals representing 19 different organizations. During this reception, the most cited skill new graduates required to be successful was a team work mindset (38\% of comments), which was defined as the ability to interact effectively with others.

Accreditation bodies echo the sentiments of industry, recognizing that working effectively in teams is an essential skill that must be developed over the course of an engineering degree program. This ability is not only an integral accreditation requirement across Canadian and US institutions [4, 5], it is also a critical career skill from which students will continue to reap the benefits long after graduation [6]. Both the Engineers Canada Accreditation Board (ECAB) and the Accreditation Board for Engineering and Technology (ABET) recognizes that the capacity to work independently and as a part of diverse teams is an essential skill set for engineering graduates to develop throughout their degree. $\mathrm{ECAB}$ cites Individual and Team Work as one of the 12 Canadian Engineering Graduate Attributes and ABET cites $A n$ Ability to Function on Multidisciplinary Teams as a student outcome required for accreditation.

Soft skills such as team work can be difficult to measure effectively, let alone develop in students [7]. Interestingly, a common method used to build team work skills in students is to put them in team-based projects [8]. However, simply being in a team does not necessarily develop team member skills. Indeed, individuals require tools and training to help them excel in team-based interactions $[9,10]$. There are numerous classroom and case studies showcasing specific methods to engage students in team-based learning [11, 12]; yet, little research has considered a holistic view on the student perception and experience of all team work activities commonly employed by educational institutions across cohorts. Such an extensive review of team work practices, experience, and perceptions is useful to not only provide benchmarking metrics but also to guide an overall strategy in future attribute assessment and development.

Extensive research and assessment practices on team work have been developed and validated in the field of 
Industrial Organizational (IO) Psychology, with recent research highlighting the benefits of partnering IO theories and Engineering education [13]. Accordingly, the Individual and Team Performance (ITP) lab in the Department of Psychology was commissioned by the Schulich School of Engineering (SSE) at the University of Calgary to operationalize the assessment of this team work attribute. The goal of this innovative partnership was to see the SSE become a leading Canadian institution in assessing, tracking, and enhancing the graduate attribute Individual and Team Work. Accordingly, the paper outlines our efforts to operationalize the attribute with the intention of outlining best practices for both student development and accreditation purposes.

The contribution of this paper is twofold. First, we summarize extensive qualitative and quantitative data collected from an extensive sample of an undergraduate population to highlight the ways universities may currently be supporting or hindering team work ability development. Through this we identify opportunities for advancement in attribute development. Second, we highlight the importance of taking a strategic, holistic approach to attribute assessment and development. This is a difficult undertaking that should be shared and advocated for department-wide. Our results are shared with the intention of enhancing team work experiences for Engineering students across North America, which will in turn better equip the next generation of Engineers for their future careers. We hope this research will inspire the effort to both assess and develop this attribute department-wide in other institutions, creating an open and supportive network of strategic best practices.

\section{METHOD}

\subsection{Participants}

A total of 836 students voluntarily completed the questionnaire in full, with the first 400 receiving a $\$ 5$ gift card. Of the total 836 participants, 731 consented to share their responses for research purposes. Respondents' average age was $21.34(S D=2.89$ years $)$. Of the students who reported gender, $38.3 \%$ identified as female. A total of 3 students $(0.4 \%)$ chose not to report a gender.

Students were asked to estimate how many teams they have worked on during their undergraduate degree at SSE. Respondents indicated that they had work on approximately 6.13 teams $(S D=5.46$ teams) over the course of their degree. Regarding program distribution, the largest percentage of participants identified as mechanical $(23.7 \%)$, followed by the common core firstyear students (22.8\%). Additionally, a total of $14.8 \%$ came from electrical, $14.2 \%$ from chemical, $14.0 \%$ from civil, $4.2 \%$ from geomatics, $3.4 \%$ from oil and gas, and finally, $2.9 \%$ from software.

\subsection{Survey Creation}

A small team of graduate and undergraduate research assistants from the psychology and engineering faculties worked together to create the assessment. This survey development team conducted extensive research on accreditation standards, past and current assessments of attribute development, team work attitudes, and attribute development practices. This combined research effort resulted in 40 Likert-scale items and 3 open-ended response questions.

\subsection{Quantitative \& Qualitative Analysis}

All quantitative analyses were conducted by a trained graduate student from the ITP lab. A Mahalanobis Distance test was conducted to identify careless responding and resulted in the removal of one participant from analyses.

For the qualitative analysis, three open-ended questions were divided and coded by four research assistants from the ITP lab. Coders individually reviewed 20 responses, creating four initial independent coding schemes. The coders then combined similarities and discussed examples to calibrate their coding responses resulting in the creation of a single coding key that all coders referred to.

Each participant response to a question was allowed a maximum of three codes to capture multiple themes but to also limit the number of codes per participant. Each of the three codes consisted of a general overarching theme (e.g., courses), followed by a more specific sub-theme (e.g., capstone or intro course). The presence of subthemes and potential for three codes per participant means that the total frequency of coded themes occurring could exceed the total number of participants.

After the coding, each individual coder was assigned 10 random participants from another coder's section and asked to cross-code the responses. This resulted in an acceptable inter-rater agreement score of .86 for crosscoded sections and confidence in the coded responses.

\section{RESULTS \& DISCUSSION}

\subsection{Quantitative Results}

The first noteworthy finding related to supporting female students in team work activities (see Figure 1). Females reported statistically significant lower levels of satisfaction with team projects $(M=3.42 ; S D=.78)$ compared to their male counterparts $(M=3.67, S D=.75$; $F=16.96, p<.001)$. Females also reported significantly lower competence in effectively engaging in the six behaviours $(M=3.31, S D=.80)$ compared to male 
students $(M=3.54, S D=.80 ; F=14.27, p<.001)$. Further study is needed to pinpoint why women reported feeling less interested in teams and less competent in their team work ability. Previous research has suggested that females generally describe feeling less confident in their "soft skill" abilities than their male counterparts [14]. However, there is also research that supports incidents of females being treated differently in male-dominated occupations. Seron and colleagues [15] found that females tended to be placed in administrative, communication, or leadership roles and were not utilized or given the chance to practice in technical roles. If females are not feeling included or given the same opportunities to practice technical skills, it would explain the lower levels of satisfaction with team projects. Alternatively, it could indicate a different learning style preference as it relates to team-based learning, whereby females prefer more of a focus on "professional" or "soft" skills to complement their technical training [14] than what is currently being offered. Our findings alone do not allow a conclusion either way; however, it does point to a research question that requires further investigation.

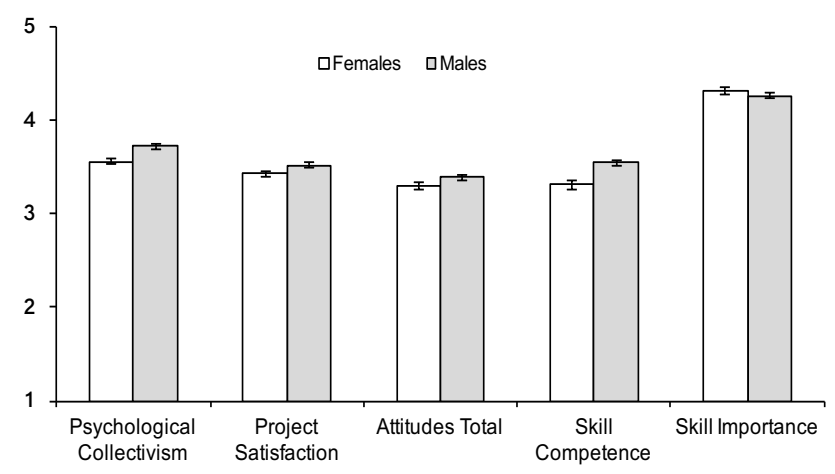

Fig. 1. Gender differences across various survey variables. Error bars represent standard error of measurement.

A second finding of interest is the gap between the perceived self-efficacy across the six team work competencies and the perceived importance of these skills for career success (see Fig. 2). Compared to perceived competency, students rated the importance of the six behaviours for career success significantly higher, with an average of $4.28(S D=.65 ; t=21.65, p<.001)$. This aligns with previous work that found while students agreed on the high importance of interpersonal, team work, communication, and problem solving skills, they do not feel competent in those areas $[14,16]$. These results highlight the understanding by students that they need to effectively display team work competencies to excel in their future careers and motivation to engage in them. Despite the importance to career success, they do not feel confident in their ability to engage in these behaviours, suggesting a need for more inclusion and focus of this attribute development.

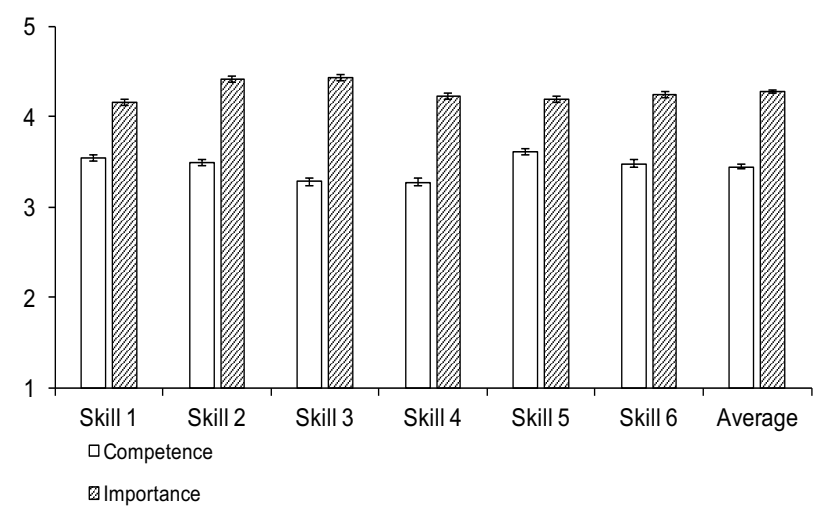

Fig. 2. Perceived competence and importance across skills. Error bars represent standard error of measurement.

A final finding regarded differences seen across program years. Specifically, there appeared to be a general buffer of positivity towards team work in first year students. First year students indicated higher satisfaction with team projects $(M=3.79, S D=.75 ; F=$ $4.30, p=.002)$ compared to third $(M=3.49, S D=.80)$ and fourth $(M=3.50, S D=.72)$ year students. Additionally, students identified as being in the first year had the highest levels of overall satisfaction, psychological collectivism, and perceived emphasis and support by SSE. This highlights the positive reinforcement of team work in the common core program, which has a large team focus. However, the decrease in satisfaction after the first year highlights a potential uneven promotion of team work attributes across the undergraduate degree. This presents a potential opportunity for emphasis of the attribute in the middle years of the program courses to sustain a high level of satisfaction with team work activities across years.

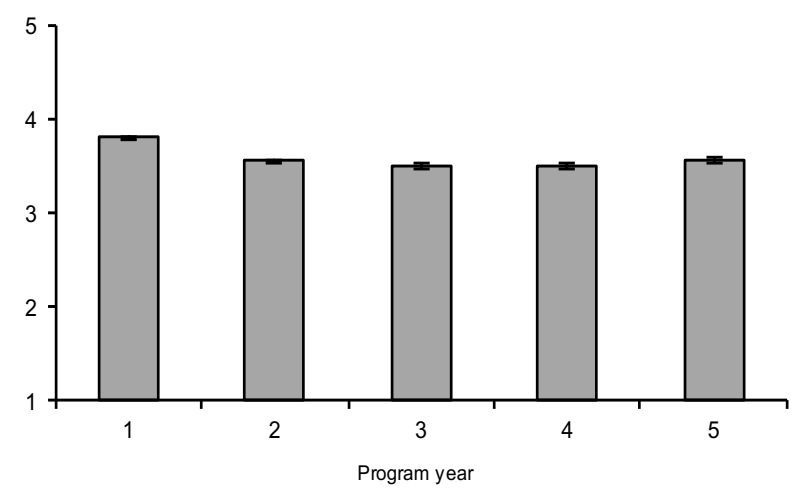

Fig. 3. Differences in team work satisfaction across program years. Error bars represent standard error of measurement. 


\subsection{Qualitative Results}

Over 2100 written responses were reviewed, coded, and categorized into themes. Specifically, theme frequencies provide insight into students' team work challenges, areas where students believe institutional support of team work could improve, and perceptions of current program strengths regarding team work.

3.2.1 Team work Challenges. The first open ended question was, "Describe the most significant challenge you face during your team work experiences at SSE."

The largest theme emerging from the challenges students face in team work was Individual Differences \& Interpersonal Conflicts with team members. Within this theme, levels of motivation and effort on the part of team members as well as communication and conflict management styles were the largest concerns. More specifically, individuals struggled with apathetic team members who were more concerned with minimizing their effort than maximizing the quality of a project. This suggests the potential for targeted workshops regarding individual work styles (e.g., conflict management).

The struggle of individual differences is highlighted further in the theme of Contribution Equity, which comprised $25 \%$ of the responses. Within contribution equity, social loafing by team members and conflict around workload distribution were prominent.

At $16 \%$ of responses the third largest theme, Timing, highlighted the challenges students face to not only find time to schedule team-based work in their compact schedules, but also to meet the deadlines proposed to them. This suggests that there may be merit in exploring different classroom structures (e.g., blended learning) where team-based projects are implemented.

A noteworthy category that emerged within this theme was sexism. Although small in frequency, the fact that any students are identifying it as the most significant struggle in their team work experiences suggests it should be considered and supports the previous findings regarding females being less satisfied with team activities. Given the limited number of females in STEM, it calls attention to the need to make more of an effort to ensure that females are given equal opportunity to participate and become proficient in the skills they need to be successful in engineering when in teams.

3.2.2 Improvement Points. The second question was, "What could the SSE do to improve team work?"

The most prominent theme to emerge was Team Work in Courses (24\%). Interestingly, the clear majority of these responses described enjoyment of the existing team projects and a desire for more team-based projects in courses to improve team work experiences in SSE. Comments suggested students valued meaningful projects when working in teams. Specifically, this theme highlighted a desire for projects that are more applicable, tied to industry or real-world outcomes, or tied to presentations of final projects (e.g., conferences, Science fairs, etc.).

Contribution Equity was the second most frequently mentioned theme, comprising $20 \%$ of total responses. Within this theme, students communicated a desire for individual grade assignment. This desire stems from current grading procedures that do not capture project contribution, which can result in students who had not contributed adequately receiving the same grade as students who had made large contributions to the project.

Along the lines of individual grades, students also expressed a desire for more peer feedback. Opportunities to give and receive peer feedback are perceived as valuable and recognize the desire to bring attention to those who are not contributing their fair share. This is further supported by the emergence of issues with workload distribution that were previously mentioned. More specifically, students commented that some projects did not lend themselves to being divided equally among groups, which resulted in some group members being required to shoulder more of the workload or there not being enough work to divide equally between members. This suggests value in reviewing current projects with a lens of attribute development.

With $14 \%$ of total responses, the main theme of Activities speaks to students' interest in having more opportunities to improve their team work capabilities and cooperative skills through activities such as team training workshops. Leadership skills were also mentioned as an area of interest. Additionally, there was interest in participating in more team building activities and competitions, which would foster team cohesion and trust.

3.2.3 Praise Points. The final open-ended question was, "What is the SSE currently doing to support team work?"

The largest number of responses, accounting for 39\% of the total comments for this question, reflected the courses being offered by SSE that utilize teams. Specific attention was given to the introductory courses and capstone courses, which contain heavily weighted team components. This is consistent with the quantitative findings across program years with the highest satisfaction in first year, followed by fifth year. Students also mentioned that presentations and meaningful projects were coursework elements that they found to be supportive of team work. This suggests that team-based projects offered in courses are well-received by students. It also adds further support to the desire for the incorporation of more presentations and meaningful projects seen in Question 2.

Accounting for $12 \%$, the theme of Teaching Staff reflects the positive ways that professors and teaching assistants are impacting students' team work experiences. Students recognized the teaching staff for their 
knowledge, responsiveness, guidance, and availability. Along with teaching staff resources, students recognized the resources available to them to support team work such as clubs and workspaces.

Taken together, the survey results suggest that SSE appears to be doing well in supporting the development of team work competencies in its students; however, there are opportunities for improvement.

\section{FUTURE RECOMMENDATIONS}

Based on these findings, we provided 12 evidencebased recommendations to support the Individual and Team Work attribute. These best practices focus on future assessments of team work competencies, the development of team work skills, reviewing the ways in which teambased projects should be implemented, and fostering a teaching and learning culture around team work.

\subsection{Team Work Competency Assessment}

4.1.1. Comprehensive Assessment Implementation. The value of the results of this survey cannot be overstated; however, the current findings need to be interpreted with caution. The voluntary nature of the survey allows for bias in those who chose to complete the questionnaire. Additionally, not all programs within the department are adequately represented in the survey. To become a leading institution in the assessment and development of team work competencies, there should be department-wide dedication to and implementation of assessments of team work competencies. Online platforms, such as ITP Metrics, allow instructors comprehensively to assess teams. Collecting additional data from students across years and programs will allow for more definite conclusions on the true state of team work competencies. It will also allow targeted research on genders, years, or programs for specific aspects of team work development.

4.1.2. Peer Feedback. To reduce contribution inequity, instructors often utilize peer feedback as a method to produce fairer grades [17]. However, administrators must be careful in utilizing peer evaluations for grades due to the biases that can occur when rating others (e.g., friendships) irrespective of their contribution to a project. Thus, a peer rating can say more about the rater than the ratee [18]. This can create a sense of injustice when peer evaluations are used for administrative purposes [19].

Alternatively, in providing the opportunity to give and receive feedback for developmental purposes, a sense of procedural justice is maintained whereby students are given an opportunity to voice their concerns. Interestingly, even the exposure to filling out a peer feedback survey has been found to change participant behaviours for the better [20]. In providing multiple opportunities for feedback, team work competencies can be tracked over time and students can practice giving and receiving feedback, which is a norm in modern workplaces.

4.1.3. Rubric Accountability. Given the issues that can result from the utilization of peer feedback for grading purposes, the need to address social loafing and unfair work distribution in teams remains. One potential way is to build in accountability measures in assignment rubrics.

Rubrics explicitly state, to the teaching team and students, the criteria used to judge the work and support consistency in marking by having a common set of criteria and descriptors for the quality of work. Clear descriptors provide the opportunity for students to identify who did what percentage of each project deliverable and for teaching staff to quickly flag individuals or teams who may require intervention. Peer feedback can be used in in conjunction with rubrics to provide more information that can inform students about their achievement level and team contributions. Various resources for detailed and adaptable rubrics are available to teaching staff (e.g., University of Toronto Learning Outcomes Project).

\subsection{Team Work Skill Development}

4.2.1. Interpersonal Skill Development. Understanding how to effectively communicate and have difficult conversations is a critical skill for effective team work. The gap between the perceived skill level and level of importance to career success highlights an opportunity to teach students how to have difficult, constructive conversations with others. Equipping students with these skills can also help limit students' dependence on a superior to mediate conflict, thereby decreasing time spent by teaching staff solving interpersonal issues.

Workshops can be created and delivered to help students learn skills to effectively communicate constructive criticism in a supportive way. These workshops can include communication tools such as techniques on how to confront difficult conversations. Inperson workshops provide the opportunity to practice techniques and observe others using various tools, but they could also be delivered online. Facilitators could work closely with professors to integrate the skills into current curriculums to reduce the extra workload on students and teaching staff while promoting a culture of respectful interpersonal interactions.

4.2.2. Individual Work Styles. Several students identified individual differences and interpersonal conflict as the largest challenges they face in team-based learning. This suggests an opportunity for targeted workshops regarding individual work styles (e.g., personality as it 
relates to team dynamics, conflict management, team role preferences, etc.). Workshops could be structured to build awareness and understanding about personal work styles of their team members. For example, Conflict Management Styles could bring awareness to how individuals are likely to approach and be approached by others in a conflict situation [21]. This could help team members adapt their communication style within the team. In building awareness of personal communication styles as well as the styles of others, individuals can be more effective in working collaboratively with similar and different style preferences.

4.2.3. Team Building. Where team training is competency-focused, team building emphasizes the interpersonal relationships within a team. Team building helps build trust and cohesion within a group, promoting the development of a team social identity $[22,23]$. One simple way that instructors and TAs can promote team building is through quick ice-breaker activities that kick off each team project or lab session. One example of an ice-breaker activity is using trust or empathy building questions that can be asked at the start of each meeting. This type of activity helps to encourage a sense of friendship by allowing team members to learn about each other's personal lives such as hobbies, likes, dislikes, personal values, and culture. In getting to know others on a personal level, one can also simultaneously promote empathy and understanding, which has been identified as a core competency for Engineers to develop [24].

\subsection{Curriculum Structure Review}

4.3.1. Blended Learning Classrooms. One way to address the scheduling challenges students identified is through the implementation of blended learning and flipped classroom techniques. Blended learning combines independent learning, often online-based, with group or hands-on application exercises [25]. In a formally flipped or inverted classroom model, traditional lecture material is studied independently ahead of class time, and inperson lectures are reserved for group work, collaboration, hands-on learning, and in-depth problemsolving. This format is becoming increasingly used within engineering education [26], with flipped classrooms having produced positive learning outcomes [27]. The degree to which a classroom is flipped should align with the class curriculum, as some class information may be better suited to a semi-flipped style [27]. Blended learning or flipped classrooms models could provide teams with a formalized time to collaborate, discuss, and complete tasks, addressing the challenge of deadlines and scheduling difficulties across varied timetables.

4.3.2. Role Rotations. The structured rotation of roles within a team project or across projects within a semester would provide each member an opportunity to experience and learn from different positions. Students with strong communication skills tend to gravitate towards the roles of organizer, writer, and presenter while other team members address the technical solutions and challenges. This prevents those with weaker communication skills from developing those abilities, while keeping strong communicators from developing their technical engineering knowledge and application. The literature shows this is especially relevant for females who are often relegated to non-technical roles within a team (e.g., communication or note-taking) [28]. In addition, single set roles, whether formal or informal, also prevent all team members from developing their leadership qualities. This can also be problematic for individuals with different cultural norms and may not be as assertive in expressing their desire to take on a specific role.

The inclusion of formal roles that are fulfilled on a rotating basis could prevent the cultural or gender segregation of roles, giving each team member the chance to explore different positions that they may not have normally considered. For example, a weekly or twice-amonth rotation between Project Manager, Communication Manager, Technical Design Lead, and Technical Test Lead roles would allow each team member to attempt every role without a) potentially jeopardizing team success, which may be the case if students are randomly assigned to roles, or b) succumbing to stereotypical or personally preferred roles.

4.3.3. Restructuring Team Projects. With accreditation in mind, educators may feel that incorporating student teams into their courses, without consideration of their purpose or learning outcomes, will address the Individual and Team Work attribute. However, team work requires interdependence, whereby individuals rely on one another to complete their assigned tasks. Not every project requires interdependence, and as such, not every project requires a team. Accordingly, current team projects should be reviewed to determine the interdependent nature of the assignment and if it is necessary to be done in a team or if it can (and should) be done independently [13]. In laboratory settings, where the primary purpose of working in groups is to alleviate resource pressures (e.g., machines, marking, etc.), the purpose of the group work would should be clear and grading should recognize individual contribution if it is not an interdependent project.

Additionally, minimal guidance is provided to students on group development, soliciting member input, consensus building, resolving conflict, and team leadership [29]. Consequently, instructors can fail to capitalize on the benefits and learning of team-based projects [30]. In projects that are deemed appropriate for collaborative learning, teams should be provided with 
relevant training and support to operate effectively in that team (e.g., team training) [29].

\subsection{TEACHING \& LEARNING CULTURE}

4.4.1 Consistent Team Work Emphasis. The results of this report suggest that the focus on team-based experiences fall either in the first year or capstone projects. This is supported by the satisfaction of teambased projects being significantly higher in first year students. It is also highlighted in the lack of any midprogram courses being referenced in the third open ended question, whereas the intro and capstone courses emerged as specific sub-themes. Thus, there is a need to review how teams are utilized and emphasized throughout the degree program, with special attention given to mid-year courses, as a more consistent emphasis across years will result in a more impactful development.

4.4.2. Student Learning Engagement. Comments by students suggest an opportunity to explore learning engagement. The current work load and tight deadlines of the engineering undergraduate degree, in addition to external pressures and commitments, likely does not allow students to prioritize quality over completion, which encourages a "good enough" attitude reported by students. There are, however, ways in which students can be motivated to engage in the required team projects.

One potential way to promote student engagement is to renew outdated and recurrent project ideas with fresh and diverse projects. Student engagement can be further amplified if the projects are meaningful or relevant to students (e.g., service learning). Specifically, new projects should positively impact society and/or the lives of others, as this can increase internal motivation [31]. Recent research has also found that students are more likely to care about a project when it challenges them and is relevant to their interests and hobbies [32]. The creation of new project ideas will also help to reduce plagiarism or "road-mapping," whereby students copy assignments from previous years. While this can create some work on the part of instructors, it could serve to rejuvenate engagement from the teaching staff and students alike.

When creating new projects targeting student engagement, avenues to explore include: social entrepreneurship, service-learning, corporate partnerships, presentation opportunities, and multi-disciplinary teams. The creation of more meaningful projects that can have a positive impact on the community or an in-need population through social entrepreneurship and servicelearning could motivate those students with a serviceorientation [33]. Alternatively, some students may be engaged by the chance to solve real-world problem with an organizational partner. The engagement of corporate partners is especially relevant because it provides students a project that has the potential to extend beyond the classroom [32]. Further, presentation opportunities such as community science events or student conferences allow students to showcase the time and energy devoted to a project over the semester or year. Finally, the inclusion of multi-disciplinary team projects is an avenue to explore beyond a capstone course. Disciples could also extend to other departments (e.g., Business Entrepreneurship) or even beyond the university. One model of incorporating global, multi-disciplinary teams and engaging industry partners is X-Culture (http://X-culture.org/). This program links globally-distributed business student teams to work on problems presented by corporate partners. Although it is recognized that implementation of multi-disciplinary teams would be difficult, it would likely better prepare students for authentic industry experience [13].

4.4.3. Professor and Teaching Assistant Training. Although small in frequency, the emergence of a sexism theme requires attention, with a focus on the staff who have the most face-to-face time with students.

There is a desire to treat female students in STEM fields equally relative to their male counterparts [34]. However, there may be situations where females' technical learning opportunities are being limited within the team, requiring an equitable intervention. Research suggests that women are often assigned or take on administrative roles instead of getting/taking the opportunity to build their technical skills [28]. Additionally, females may feel frustrated by not getting the opportunity to take on an administrative, management, or communication role that they feel they could excel at to boost their team grade [28]. It is possible that there could be perceived unfairness in assigning technical roles to females over males; however, this sense of unfairness could also be addressed through role rotation.

All teaching staff should be equipped with the knowledge and tools to spot potential situations that could be resulting in not all team members getting equal opportunities to learn a specific skill or take on a different role within the team. Even going so far as to making a clear announcement at the start of the semester about a zero tolerance policy for segregating comments or action and an open door policy for any student who feels they are being segregated, marginalized, or missing out on learning opportunities due to gender or culture.

\section{CONCLUSION}

Working effectively in teams is a critical skill that must be developed over the course of an engineering degree program. This ability is not only an integral accreditation requirement: it is an essential career skill from which students will continue to reap the benefits long after graduation. The qualitative and quantitative results of this survey capture the current state of the Individual and Team Work attribute development across 
an entire Engineering department and identify opportunities for improvement. Our findings highlight the importance of taking a holistic and strategic approach to attribute assessment and development to enhance team work experiences for Engineering students. Although specific to the results of a single institution, the resulting 12 recommendations could act as a valuable guide to other Engineering programs seeking to enhance students' team work attribute assessment and development.

\section{Acknowledgements}

Special thanks to the Research Assistants and Graduate students of the Individual and Team Performance lab and Schulich School of Engineering who contributed invaluable time and energy to various aspects of this survey and report. Specifically, Claire Ferguson, Julia Smith, Emily Marasco, and Nicole Larson, who assisted the survey development team, as well as Denise Law and Christianne Varty, who contributed to the coding of the qualitative survey responses, should be acknowledged.

\section{References}

[1] Steve W. J. Kozlowski and Bradford S. Bell, Work Groups and Teams in Organizations. New York: Wiley, 2003, 42 $\mathrm{pp}$.

[2] Samantha R. Brunhaver, Russell F. Korte, Stephen R. Barley, and Sherri D. Sheppard, Bridging the gaps between engineering education and practice. University of Chicago Press, 2017,32 pp.

[3] Chenicheri Sid Nair, Arun Patil, and Patricie Mertova, "Reengineering graduate skills-a case study", European Journal of Engineering Education, vol. 34, no. 2, pp. 131-139, 2009. Available as of April 23, 2009 from http://www.tandfonline.com/doi/abs/10.1080/030437909028 29281

[4] Accreditation Board for Engineering and Technology, Inc. (2016). Criteria for accrediting engineering programs. Retrieved from http://www.abet.org/wpcontent/uploads/2016/12/E001-17-18-EAC-Criteria-10-2916-1.pdf

[5] Board for Engineering and Technology, Inc. (2016). Criteria for accrediting engineering programs. Retrieved from http://www .abet.org/wp-content/uploads/2016/12/E001-1718-EAC-Criteria-10-29-16-1.pdf

[6] The Conference Board of Canada (2000). Employability $\begin{array}{lll}\text { Skills } & 2000+. & \text { Retrieved }\end{array}$ http://www.conferenceboard.ca/topics/education/learningtools/employability-skills.aspx

[7] Keith Willey and Mark Freeman, "Completing the learning cycle: The role of formative feedback when using self and peer assessment to improve teamwork and engagement.", in
Proc. Australasian Association for Engineering Education Conf., Gerard Rowe and Gillian Reid (eds.) (Auckland, New Zealand; 10-13 December 2006), 9 pp., 2006.

[8] Michaelsen, L. K., \& Sweet, M. (2008). The essential elements of team-based learning. New directions for teaching and learning, 2008(116), 7-27.

[9] Thomas A. O’Neill, Genevieve Hoffart, Matthew McLarnon, Hayden Woodley, and Natalie Allen, "Constructive controversy and reflexivity training promotes effective conflict profiles and outcomes in student learning teams," Academy of Management Learning and Education.

[10] Dean Tjosvold, "Constructive controversy for management education: Developing committed, open-minded researchers," Academy of Management Learning \& Education, vol. 7, no. 1, pp. 73-85, 2008. Available as of March 2008 from https://www.researchgate.net/profile/Dean_Tjosvold/publica tion/260267778_Constructive_Controversy_for_Manageme nt_Education_Developing_Committed_Open-

Minded Researchers/links/0a85e5306d0ea66a23000000.pdf

[11] David Boud, Ruth Cohen, and Jim Sampson, Peer learning in higher education: Learning from and with each other. Routledge, 2014.

[12] Annette W. Burgess, Deborah M. McGregor, and Craig M. Mellis, "Applying established guidelines to team-based learning programs in medical schools: a systematic review," Academic Medicine, vol. 89, no. 4, pp. 678-688, 2014. Available as of February 25, 2014 from https://www.ncbi.nlm.nih.gov/pmc/articles/PMC4885587/

[13] Maura Borrego, Jennifer Karlin, Lisa D. McNair, and Kacey Beddoes, "Team effectiveness theory from industrial and organizational psychology applied to engineering student project teams: A research review," Journal of Engineering Education, vol. 102, no. 4, pp. 472-512, 2013. Available from http://s3.amazonaws.com/academia.edu.documents/4628971 8/Team_Effectiveness_Theory_from_Industria2016060617189-

7ga2py.pdf?AWSAccessKeyId=AKIAIWOWYYGZ2Y53U L3A\&Expires $=1493958345 \&$ Signature $=$ foiaxZVIGb13q7d Lsz8I9\%2Fg\%2BuE8\%3D\&response-contentdisposition=inline \%3B\%20filename\%3DTeam_Effectivenes s_Theory_from_Industria.pdf

[14] Hyun Kyoung Ro and David B. Knight, "Gender differences in learning outcomes from the college experiences of engineering students," Journal of Engineering Education, vol. 105, no. 3, pp. 478-507, 2016.

[15] Carroll Seron, Susan S. Silbey, Erin Cech, and Brian Rubineau, "Persistence is cultural: Professional socialization and the reproduction of sex segregation," Work and Occupations, vol. 43, no. 2, pp. 178-214, 2015 .

[16] Nguyen Danh Nguyen, Yanagawa Yoshinari, and Miyazaki Shigeji, "University education and employment in Japan:

CEEA17; Paper 28 
Students' perceptions on employment attributes and implications for university education," Quality Assurance in Education, vol. 13, no. 3, pp. 202-218, 2005.

[17] Filip Dochy, M. Segers, and D. Sluijsmans, "The use of self-, peer and co-assessment in higher education: A review," Studies in Higher Education, vol. 24, pp. 331-350, 2006.

[18] Brian Hoffman, Charles Lance, Bethany Bynum, and William Gentry, "Rater source effects are alive and well after all," Personnel Psychology, vol. 63, no. 1, pp. 119-151, 2009. Available as of December 31, 2009 from https://www.researchgate.net/profile/Chuck Lance/publicati on/229922176 Rater source effects are alive and well af ter all/links/566c85bd08ae62b05f08823c.pdf

[19] Ramona D. Bobocel and Leanne Grosse, "Procedural justice: A historical review and critical analysis," Organizational justice: Where we have been and where we are going. NY: Oxford University Press, 2015, 36 pp.

[20] Peter G. Dominick, Richard R. Reilly, and Jack W. Mcgourty, "The effects of peer feedback on team member behavior," Group \& Organization Management, vol. 22, no. 4, pp. 508-520, 1997. Available from http://journals.sagepub.com/doi/abs/10.1177/105960119722 $\underline{4006}$

[21] Afzalur Rahim and Thomas V. Bonoma, "Managing organizational conflict: A model for diagnosis and intervention," Psychological Reports, vol. 44, no. 3, pp. 1323-1344, 1979.

[22] Blake E. Ashforth and Fred Mael, "Social identity theory and the organization," Academy of Management Review, vol. 14 , no. 1 , pp. 20-39, 1989. Available from https://www.researchgate.net/profile/Blake Ashforth/public ation/233729899 Social Identity Theory and Organizatio n/links/583c91ee08ae502a85e3e966/Social-Identity-Theoryand-Organization.pdf

[23] Amanda Deacon, Thomas A. O'Neill, and Kartikeya Murari, "Team membership change and the critical role of communication," in Proc. Annual American Society for Engineering Education Conference (New Orleans, LA; June 2016).

[24] Joachim Walther, Shari E. Miller, and Nicola W. Sochacka, "A model of empathy in engineering as a core skill, practice orientation, and professional way of being," Journal of Engineering Education, vol. 106, no. 1, pp. 123-148, 2017.

[25] Garrison, D. R., \& Kanuka, H. (2004). Blended learning: Uncovering its transformative potential in higher education. The Internet and Higher Education, 7(2), 95-105.

[26] Stephanie Butler Velegol, Sarah E. Zappe, and Emily Mahoney, "The evolution of a flipped classroom: Evidencebased recommendations" Advances in Engineering Education, vol. 4, no. 3, pp. 1-37, 2015. Available from http://advances.asee.org/wp-
content/uploads/vol04/issue03/papers/AEE-15-Velegol.pdf

[27] Renee M. Clark, Autar Kaw, and Mary Besterfield-Sacre, "Comparing the effectiveness of blended, semi-flipped, and flipped formats in an engineering numerical methods course," Advances in Engineering Education, vol. 5, no. 3, pp. 1-39, 2016. Available from http://advances.asee.org/wpcontent/uploads/vol05/issue03/Papers/AEE-19-FlippingKaw.pdf

[28] Jennifer Bradley-Heflin, Colleen Newman, Kelly O’Brien, Brooke Ybarra, Deborah Kissire, and Jeanine Turner, (2010, April 23). The female compiler phenomenon: Women choosing critical, but invisible roles in small groups. Retrieved from http:/guwli.georgetown.edu/wpcontent/uploads/2014/04/b.-Research-1-ResearchCompetition female- compiler.pdf

[29] Karl A. Smith, Sheri D. Sheppard, David W. Johnson, and Roger T. Johnson, "Pedagogies of engagement: Classroombased practices," Journal of Engineering Education, vol. 94, no. 1, pp. 87-101, 2005. Available from http://kbsgk12project.kbs.msu.edu/wpcontent/uploads/2011/02/Smith-2005Pedagogies of Engagement.pdf

[30] Douglas W. Jones, "Empowered teams in the classroom can work," Journal for Quality and Participation, vol. 19, no. 1, pp. 80-86, 1996.

[31] Yitzhak Fried and Gerald R. Ferris, "The validity of the job characteristics model: A review and meta-analysis," Personnel Psychology, vol. 40, no. 2, pp. 287-322, 1987.

[32] Emily Marasco, Laleh Behjat, and Marjan Eggermont, "Engaging first year students through crossdisciplinary design projects," in Proc. Canadian Engineering Education Association Conference, (Canmore, AB: June 2014).

[33] Alexander W. Astin, Lori J. Vogelgesang, Elaine K. Ikeda, and Jennifer A. Yee, "How service learning affects students," Higher Education, Paper 144. Retrieved from http://digitalcommons.unomaha.edu/slcehighered/144

[34] Stephanie G. Adams, "Building successful student teams in the engineering classroom," Journal of STEM Education: Innovations and Research, vol. 4, no. 3/4, pp. 1-18, 2003. Available from https://www.researchgate.net/profile/Stephanie Adams9/pu blication/238696668 Building Successful Student Teams in the Engineering Classroom/links/5448872d0cf22b3c14e 311ca.pdf 